\title{
How Lucky We were in remembrance of Pierre Hohenberg
}

\author{
W. F. Brinkman ${ }^{1}$
}

Received: 28 September 2018 / Accepted: 9 October 2018 / Published online: 24 October 2018 (c) The Author(s) 2018

For many of my Physics colleagues, the years we spent in the Bell Laboratories Research Organization during the last four decades of the 20th century were extraordinarily special and Pierre Hohenberg who was there from 1964 until 1995 was an important part of it. Bell Labs was a place that allowed us an unusual amount of freedom to pursue our interests in science in a totally immersive way without other duties or distractions. It had an open environment in which one tried ideas on colleagues often gaining information that helped further your own research. Because the scientists came from all over the world it was an international community that created its own social environment outside the labs as well as within.

This environment was not created over night but resulted from the revolution in science in the 20th century. After the role that science played in WWII with the invention of radar and the atomic bomb and with the invention of the transistor in the late 1940's there was the perception that one could simply plant the seeds of science and watch the plants grow. Bell Labs research was the result of these attitudinal changes. It evolved from a company that needed technology to create the telephone systems it managed and consequently did much applied research starting at the beginning of the 20th century. Bell Labs played a large role in WWII working on radar and other military advances. During the 1950's the research staff gradually made the management aware that if you are doing basic research you are competing with university research and therefore needed the freedom to pursue research in an open fashion going to meetings on science around the country and the world.

When my generation of scientists came to Bell Labs mostly in the 1960's to the 1970's the culture of basic research was well established and lasted until around 2000 when the dotcom collapse caused Lucent Technologies to combine with Alcatel and greatly reduce its spending on research. Let's examine some of the cultural attributes in more detail.

Without question the openness of the staff was one of the most essential cultural characteristics that made Bell Labs a special place to be. For many years we enjoyed 4:00 pm tea where we got together and discussed physics from many points of view. In fact, the only paper I wrote with Pierre was the result of a conversation we had during tea regarding sum rules and how they worked in one dimensional systems. Visitors often joined us at tea. Once David Thouless was visiting and we discussed metal-insulator transitions and he greatly helped my thinking of the subject. In addition, the lunch tables were an important place where physics was discussed and argued. Phil Anderson saw these lunches as so important to him that he insisted on going to lunch with all of us on the day he was awarded the Nobel Prize. Maurice

$\bowtie \quad$ W. F. Brinkman wfb@princeton.edu

1 Princeton University, Princeton, USA 
Rice and I got the idea for our most important joint paper on metal Insulator transitions over lunch one day. This open atmosphere was one of the real advantages of being at the labs. When we first arrived at Bell Labs Conyers Herring, who was an avid reader of the literature, had a large black suitcase in which he kept post card sized notes on papers he had read all filed by subject matter so that he could quickly look them up. If you wanted to find the latest papers on a given subject you simply went to Conyers and asked what papers he thought were best on the subject. It was a great way to get started.

It was of utmost importance to have a management that understood the science that was being performed and could make sound judgments of its quality. Thus the entire management from department heads to vice presidents were scientists. Of utmost importance was the recruiting the best young scientists. The labs had an extensive recruiting program where the members of staff were assigned to recruit at the major universities throughout the world. This insured the labs of high quality young recruits. When candidates were brought to the labs for an interview they interacted with a selection of staff members and a consensus on their ability was developed quickly so that an offer could be made within a few days. Since we were competing with universities who were not able to move so quickly this gave the labs a tremendous advantage. The process had other flexibilities. For example, Doug Osheroff agreed to come to the labs after discovering Superfluidity in ${ }^{3} \mathrm{He}$ at Cornell but would be finishing his thesis over the summer so the labs allowed him to order his equipment in the spring so he would be ready to start when he arrived in the fall.

The management also did annual reviews of the work of all the staff. It used its judgement to decide on salaries of each individual creating a factor of two between the highest and lowest paid staff members. Even so all salaries were sufficient to have a good life in the New Jersey suburbs or even in New York City where Pierre spent his life after joining Bell Labs. If the management decided that someone was not performing up to the level expected it would usually simply ask the person to leave by the next fall so that they would have time to find a faculty position. By this means the staff member did not really get fired and could pursue his/her career without any stigma.

The culture was clearly focused on younger scientists and the standard view of careers among the staff members was that one spent 5-10 years at the labs and then went to a university into a tenured position. This led to a large population of university professors that were formerly at the labs. There are many examples, Bert Halperin at Harvard, Patrick lee at MIT, Bob Birgeneau at Berkeley and Phil Anderson at Princeton. Unfortunately, this population is now getting older since this flow stopped around 1999.

There is probably no better example of the effect of Bell Labs on one's career than Pierre Hohenberg. Not long after he arrived at Bell Labs he and Bert Halperin got together and began working on scaling of dynamic critical phenomena for which both became well known. They stimulated much work on this phenomena and they both have had very successful careers.

Phil Anderson was clearly the leader of the theorists at the labs for many years. He seemed to know how to develop new theories as discoveries in experiments challenged the theoretical knowledge we possessed. Whether it was the attractive Hubbard Model, the spin glass model, the Anderson model of a magnetic impurity, the pairing model for high temperature superconductors or ideas about localization he was always the leader. He left the rest of us with plenty of research to do.

One of the people who made the place a fun place to be was Phil Platzman. He was the head of an experimental department that did outstanding research and Phil was always supportive and continuously challenged you to make sure your research made sense to him. He had Bob Birgeneau and Peter Eisenberger in his group. Bob initiated coupling to the neutron activities at Brookhaven as a way to enhance the understanding of the nature of many magnetic systems. 
Peter really started the first intense X-ray physics program at the labs which led to Bell Labs participation in the use of synchrotron radiation. The group including David Moncton had a large influence on the directions of the synchrotron radiation of this country.

As time went on others came to the labs and made prize winning discoveries. Stormer and Tsui discovered the fractional quantum Hall effect, a subject that dominated Condensed matter physics for a number of years. Steve Chu and Art Ashkin invented laser cooling of atoms. I always remember meeting Steve shortly after they had done this experiment and asking him what it was good for. He thought that was an unfair question!! Of course, it has created a major research enterprise. Seji Ogawa invented Functional MRI imaging. I remember him coming to my office and showing me pictures of a mouse brain conscious and unconscious. These discoveries won Nobel prizes and the Japan Prize. But there were so many others. Doug Osheroff delineated the properties of superfluid phases of ${ }^{3} \mathrm{He}$. $\mathrm{Al}$ Cho developed MBE technology and Loran Pheiffer took it to a new level. Federico Capasso invented the quantum casade laser which was a beautiful application of MBE technology.

One of the surprising outstanding activities was the Neutral Science group that was led by David Tank with the advice and assistance of John Hopfield. They invented various nonlinear imaging techniques, particularly two photon imaging that is used today to understand the actions of neurons in live brains.

David and his colleagues were awarded the Brain Prize in 2015. I have been told by researchers in the field that this group has had large influence on the field.

Of course, there are many other scientists that I could mention. The ones I choose are just examples but I hope they illustrate how the scientific excitement permeated the Labs for so many years and why those of us involved were so privileged to be part of this history.

Open Access This article is distributed under the terms of the Creative Commons Attribution 4.0 International License (http://creativecommons.org/licenses/by/4.0/), which permits unrestricted use, distribution, and reproduction in any medium, provided you give appropriate credit to the original author(s) and the source, provide a link to the Creative Commons license, and indicate if changes were made. 